\title{
Encapsulation of krill oil by spray drying
}

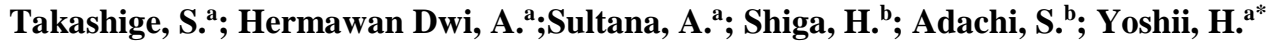

a Department of Applied Biological Science, Faculty of Agriculture, Kagawa University, 2393, Ikenobe, Miki-cho, Kita-gun, Kagawa 761-0795, Japan

b Department of Agriculture and Food Technology, Faculty of Bio-environmental Science, Kyoto Gakuen University, 1-1 Nanjo Ohtani, Sokabe-cho, Kameoka, Kyoto 621-8555, Japan.

*E-mail of the corresponding author: foodeng.yoshii@ag.kagawa-u.ac.jp

\begin{abstract}
An oil from Pacific krill (Euphausia pacifica) has a high content of PUFAs and phospholipids. The sediment was formed with homogenization of krill oil and maltodextrin (MD; dextrose equivalent $(D E)=19)$ solution using sodium caseinate, gum arabic, hydrolyzed whey protein or modified starch as a surfactant. Quillaja saponin could form the emulsion without the sediment. MD (28.5 wt\%) was solubilized with distiller water (50 wt\%) and mixed with krill oil (20wt\%) and Quillaja saponin (1.5 wt\%). The homogenized solution was spray-dried using Okawara-L8 spray dryer with a centrifugal atomizer. Spray-dried powder was evaluated in the oil-droplet size and surface-oil content.
\end{abstract}

Keywords: krill oil, emulsion, Quillaja saponin, spray drying, PUFAs 


\section{Introduction}

Krill oil (KO) is a rich souce of long chain n-3 polyunsaturated fatty acids (PUFAs) such as eicosapentaenic acid (EPA) and docosahexaenoic acid (DHA) [1], which have phospholipids, and has been suggested to have the higher bioavailability compared with fish oil. KO contains astaxanthin as antioxidant. Encapsulated KO has been used as a dietary supplement. PUFAs are inherently unstable and prone to oxidation. Gomez-Estaca et al. [2] investigated the encapsulation of an astaxanthin-containing lipid extract from shrimp waste by complex coacervation using a novel gelatin-cashew gum complex. Haidor et al. [3] investigated the encapsulation of $\mathrm{KO}$ using chitosan nanoparticle with emulsification and the electrostatic interaction to triphosphate. Sanguansri et al. [4] investigated the encapsulation of $\mathrm{KO}$ using the mixture of protein and carbohydrates by spray drying and showed the protein enhanced the oxidative stability of KO during storage. Yamada et al. [5] showed 8-hydroxyeicosapentaenoicacid (8-HEPE) acts as a peroxisome proliferator-activated receptor ligand and had higher activity than EPA. KO from the Pacific Ocean near Sanriku contained 8-HEPE.

The encapsulation efficiency of fish oil by spray drying is affected by several parameters such as oil-droplet diameter, solid and oil contents, and processing conditions. The surfaceoil ratio is the most important parameter that estimates the shelf life of fish oil in spraydried powders. Ghani et al. [7] investigated effects of oil-droplet diameter and DE of MD on the surface-oil ratio of microencapsulated fish oil and showed the surface-oil ratio was remarkably increased when the ratio of the average reconstituted oil-droplet diameter to the average particle diameter was higher than 0.01. Ghani et al. [8] investigated also the effect of $\mathrm{DE}$ of MD on oxidation stability in encapsulated of fish oil with MD by spray drying. They indicated that the fish oil in spray-dried powder encapsulated fish oil prepared using MD of DE = 25 and 19 had lower peroxidative values (PVs) than those prepared with MD of $\mathrm{DE}=11$. The difference in PV can be ascribed to the difference in the surface-oil ratio of the spray-dried microcapsules.

In this study, the formation of emulsified $\mathrm{KO}$ was investigated with various emulsifier and the stability of encapsulated $\mathrm{KO}$ using $\mathrm{MD}(\mathrm{DE}=19)$ and saponin emulsifier was examined at $50^{\circ} \mathrm{C}$.

\section{Materials and Methods}

\subsection{Materials}

KO was purchased from Koyo Chemical Co., Ltd. (Osaka, Japan). In the formation of KO emulsion, sodium caseinate, hydrolyzed whey protein, gum arabic, modified starch or saponin emulsifier were used. Sodium casienate and rosemary extract oil (RO) was gifted 
from Mitsubishi-Chemical Foods Corporation (Tokyo, Japan). Hydrolyzed whey protein, Emulup $^{\circledR}$ was purchased from Morinaga Milk Industry Co. Ltd. (Tokyo, Japan) and gum arabic was from Wako Pure Chemical Industries, Ltd. (Osaka, Japan). Saponin emulsifier was Quillayanin S-100 from Maruzen Pharmaceuticals Co., Ltd. (Hiroshima, Japan) MD (DE=19) was gifted from Matsutani Chemical Industry Co., Ltd. (Itami, Japan). Other chemical reagents used were analytical grade chemicals from Wako Pure Chemical Industries, Ltd.

\subsection{Method}

\subsubsection{Formation of $\mathrm{KO}$ emulsion}

MD solution was prepared by dissolving MD in distilled water at $80{ }^{\circ} \mathrm{C}$ and cooling to room temperature. $\mathrm{KO}$ was blended with the solution to give $50 \mathrm{wt} \%$ solid content. The composition of the solution was $20 \mathrm{wt} \% \mathrm{KO}, 1.5 \mathrm{wt} \%$ emulsifier, $28.5 \mathrm{wt} \% \mathrm{MD}$, and 50 wt\% distilled water. The solution was mixed using a rotor-stator type homogenizer (Polytron, PT-6100; Kinematica, Littau, Switzerland) at 7,500 rpm for 3 min with a $30 \mathrm{~s}$ interval after $1 \mathrm{~min}$ and $2 \mathrm{~min}$. This solution was further homogenized using a highpressure homogenizer (Star Burst Mini; Sugino Machine Limited, Uozu, Japan) at $100 \mathrm{MPa}$ for two passes.

\subsection{2. $\quad$ Spray drying}

The feed emulsions were spray dried using a pilot scale spray dryer (Ohkawara-L8; Ohkawara Kakouki Co., Ltd., Yokohama, Japan) equipped with a centrifugal atomizer. The feed rate was $25 \mathrm{~mL} / \mathrm{min}$, the atomizer speed was 10,000 rpm, and the air flow rate was set at $110 \mathrm{~kg} / \mathrm{h}$. In the drying process, the temperatures of inlet and outlet air were $140{ }^{\circ} \mathrm{C}$ and 70 to $95^{\circ} \mathrm{C}$, respaectively

. After being cooled to room temperature, the collected powders were stored in closed glass containers at $-80^{\circ} \mathrm{C}$ until use.

\subsubsection{Analysis of oil-droplet and powder-particle diameters}

The size distributions of the oil droplets in the feed and reconstituted emulsion and the spray-dried powder particles were measured with a laser diffraction particle size analyzer (SALD-7100; Shimadzu Corporation, Kyoto, Japan) equipped with a batch sample cell. The reconstituted emulsion were obtained by dissolving the spray-dried powders in distilled water. The feed and reconstituted emulsion were pipetted directly into the cell containing distilled water for respective measurements. Meanwhile, the particle size distributions of the spray-dried powders were analyzed by dispersing the powders in 2-methyl-1-propanol. The volume-based diameter $\left(D_{43}\right)$ was considered to be the mean diameter for all measurements. 


\subsubsection{Scanning electronic microscopy (SEM)}

Surface and cross-cut images of encapsulated fish oil powders were observed by a JSM 6060 SEM (JEOL, Tokyo, Japan). The samples were placed onto the SEM sample holder using double-sided tape and coated with Pt-Pd using an MSP-IS Magnetron Sputter (Vacuum Device, Inc., Tokyo, Japan). The cross-cut structures were prepared using procedure as described by Soottitantawat et al. [8].

\subsubsection{Measurement of DHA and EPA contents in KO}

Approximately $0.2 \mathrm{~g}$ of oil or $0.5 \mathrm{~g}$ of powders was weighed in the test tube. Two $\mathrm{ml}$ of $N$, $N$-dimethylformamide (DMF) was added to solubilize KO in the tube. Then, $2 \mathrm{~mL}$

of hexane was added to extract KO from DMF and was stirred with a vortex mixer (Vortex-GENIE 2 Mixer, G-560 type, M\&S Instrument Inc., Osaka, Japan). Hexane was sampled and $0.5 \mathrm{~mL}$ of $\mathrm{KO}$ was used to be methyl esterified with Fatty Acid Methylation Kit and Fatty Acid Methyl Ester Purification Kit (Nacalai Tesque, Inc., Kyoto, Japan). One $\mu \mathrm{L}$ of methyl esterified oil was injected to gas chromatography-mass spectrometry (GC-MS, Shimazu Corp., Kyoto, Japan) with a fused silica capillary column (30 m x $0.25 \mathrm{~mm}$ x 0.25 $\mu$ m; DB-1, Agilent Technologies Japan Ltd., Tokyo, Japan).

\section{Results and Discussions}

\subsection{Formation of $\mathrm{KO}$ emulsion}

$\mathrm{KO}$ emulsion was formed with quillayanin, sodium casienate, hydrolyzed whey protein, or arabia gum as $3 \mathrm{wt} \%$ emulsifier in the solid powder by the mechanical homogenization (8,000 rpm for $3 \mathrm{~min}$ ). The $\mathrm{KO}$ emulsions using sodium casienate, hydrolyzed whey protein, and arabia gum separated into two phase solution. No phase-separation occurred for the KO emulsion using quillayanin as emulsifier. Oil-droplet diameters for $\mathrm{KO}$ emulsions were measured with a laser diffraction particle size analyzer at $3 \mathrm{~h}$ after the emulsification. Except KO emulsion using quillayanin, the lower phase solution was used to measure oildroplet diameter. Figure 1 shows the distributions of oil-droplet diameter for four KO emulsions. $\mathrm{KO}$ emulsions using sodium casienate and arabia gum formed aggregates and had larger oil-droplet diameter above $10 \mu \mathrm{m}$. KO contains about $18 \mathrm{wt} \%$ phospholipids. Genelally phospholipid make aggragtion with proteins. These results show that protein emulsifier could not be used to emulsify KO. Saponin emulsifier, quillayanin was suitable emulsifier to form stable emulsion. 


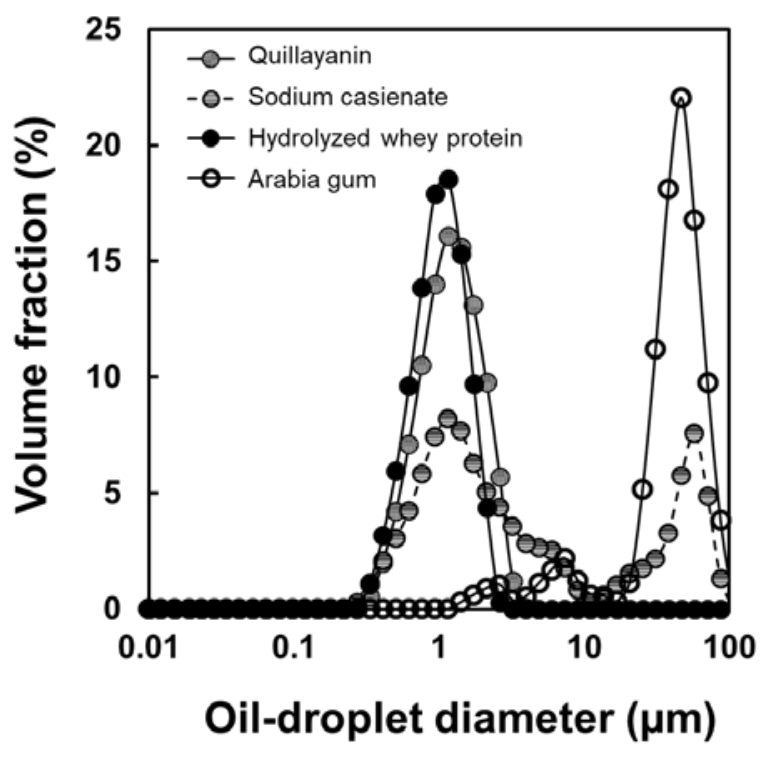

Fig. 1. Distribution of oil-droplet diameter for KO emulsion using emulsifier, quillayanin, sodium casinate, hydrolyzed whey protein or arabia gum.

\subsection{Formation of spray-dried KO powder}

By using quillayanin as an emuslifer, spray-dried KO powders were produced by two homogenization conditions, the mechanical homogenization and high-pressure homogenization. The spray-dried powder was also formed for the case where rosmary extract as an antioxidant was added to $\mathrm{KO}$ at mechanical homogenization. Table 1 shows physical properties of three spray-dried powders. Average oil-droplt diamters for three spray-dried powders were about 1.1-1.4 $\mu \mathrm{m}$. Moisture contents were about $2 \mathrm{wt} \%$ for the mechanical homogenization and 3.6wt\% for high-pressure homogenization. Reconstituted oil-droplet and powder diameters were about $1.4 \mu \mathrm{m}$ and $58 \mu \mathrm{m}$ for the mechanical homogemization and $1.1 \mu \mathrm{m}$ and $70 \mu \mathrm{m}$, respectively. Figure 2 shows SEM images of surface structures and cross-cut sructures of spray-dried powders. SEM images of crosssection structures for KO encapsylated spray-dried KO powders show clear oil-droplet distribution in spray-dried powder. 
Table 1. Physical properties od spray-dried powders.

\begin{tabular}{|c|c|c|c|c|c|}
\hline & \multicolumn{2}{|c|}{ Ko emulsion } & \multicolumn{2}{c|}{ Spray-dried powder } \\
\cline { 2 - 6 } & $\begin{array}{c}\text { Oil-droplet } \\
\text { diameter } \\
(\mu \mathrm{m})\end{array}$ & $\begin{array}{c}\text { Viscosity } \\
(\mathrm{mPa} \cdot \mathrm{s})\end{array}$ & $\begin{array}{c}\text { Moisture } \\
\text { content } \\
(\%)\end{array}$ & $\begin{array}{c}\text { Reconstituted } \\
\text { oil-droplet } \\
\text { diameter } \\
(\mu \mathrm{m})\end{array}$ & $\begin{array}{c}\text { Powder } \\
\text { diameter } \\
(\mu \mathrm{m})\end{array}$ \\
\hline $\begin{array}{c}\text { Mechanical } \\
\text { homogenization } \\
(7500 \text { rpm) }\end{array}$ & $1.31 \pm 0.04$ & $6.89 \pm 0.44$ & $2.00 \pm 0.20$ & $1.41 \pm 0.03$ & $58.3 \pm 6.10$ \\
\hline $\begin{array}{c}\text { High-pressure } \\
\text { homogenization } \\
(100 \mathrm{mPa})\end{array}$ & $0.81 \pm 0.005$ & $7.54 \pm 0.12$ & $3.58 \pm 0.36$ & $1.13 \pm 0.004$ & $70.2 \pm 1.11$ \\
\hline $\begin{array}{c}\text { Mechanical } \\
\text { Homogenization } \\
+ \text { rosemary } \\
\text { extract }\end{array}$ & $1.31 \pm 0.02$ & $18.17 \pm 0.46$ & $2.33 \pm 0.15$ & $1.40 \pm 0.003$ & $57.1 \pm 2.33$ \\
\hline
\end{tabular}
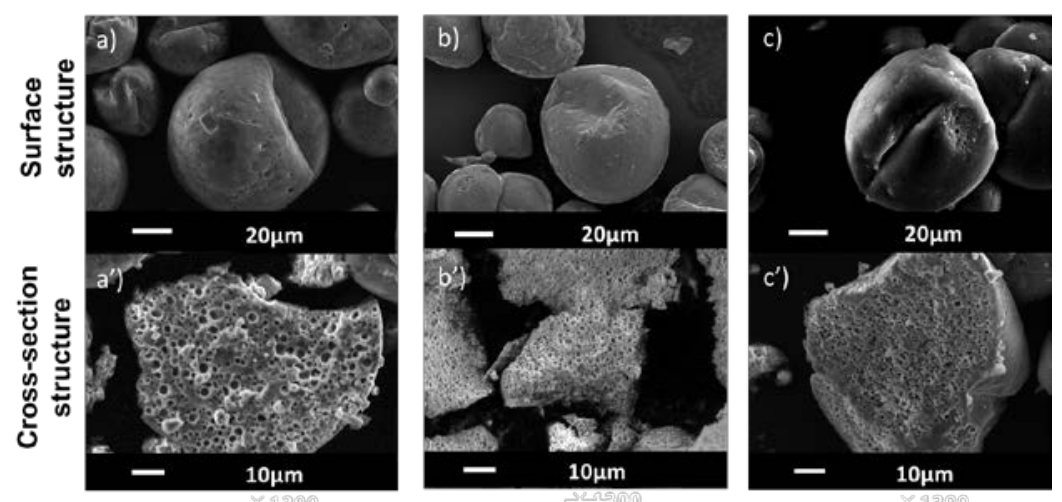

Fig. 2. SEM images of spray-dried KO powder by the mechanical homogenization ( $a, b$ and $a^{\prime}, b^{\prime}$ ) and high-pressure homogenization. KO in spraydried powder for $b$ and $b$ ' contained rosemary extract oil.

\subsection{Stabilty of EPA and DHA in spray-dried KO powder}

Stabilities of EPA and DHA were investigated in spray-dried $\mathrm{KO}$ powders at $50^{\circ} \mathrm{C}$ for oneand two-week storages. Figure 3 indicates the retentions of EPA and DHA to the intial content of EPA and DHA in KO, KO plus 5wt\% RO in KO, spray-dried KO powder by the 
high-pressure homogenization (HP), KO encapsulated spray-dried powder by the mechanical homogenization (MH), and $\mathrm{KO}$, which contined with 5wt\% RO, encapsulated spray-dried powder with $\mathrm{MH}$. The retentions of EPA about 0.4 in $\mathrm{KO}$ and $\mathrm{KO}$ contained $5 w t \%$ RO were higher than these of DHA about 0.1. The addition of RO to KO did not affect the retentions of EPA and DHA. The retentions of EPA and DHA for spray-dried KO powder by $\mathrm{MH}$ were higher than those of KO wncapsulated spray-dried powder with HP. These results sugest the force during homogenization affected the stability of EPA and DHA in KO. In spray-dried powder, RO addition improved the retention of DHA siginificantly in spray-dried powder. After two-weeks storage at $50^{\circ} \mathrm{C}$, the retentions of EPA and DHA were obtained about 0.8 in spray-dried $\mathrm{KO}(+5 \mathrm{wt} \% \mathrm{RO})$ powder. The encapsulation of KO could improve the stability of EPA and DHA. However, suitable homogenization condition and antixodant concentration should be investigated to obtain the more stable KO encapsulated spray-dried KO powder.

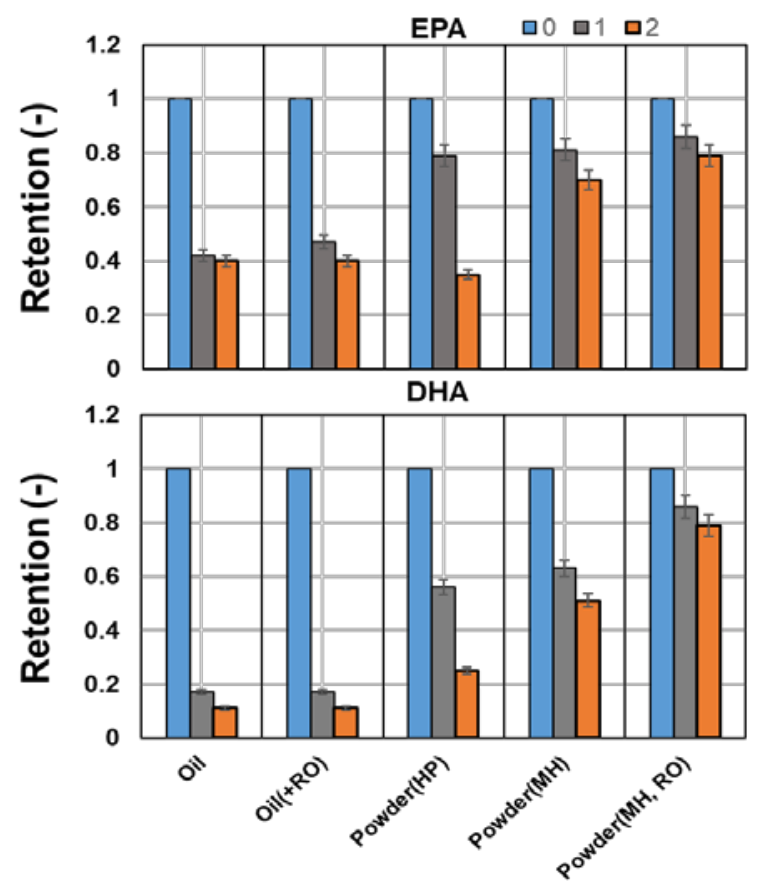

Fig. 3. Stability of EPA and DHA at $50^{\circ} \mathrm{C}$ for on- and two-week storage 


\section{Conclusions}

Spray-dried KO powder was formed by emulsification and spray drying. KO contained $5 w t \%$ RO could be encapsulated with MD $(\mathrm{DE}=19)$ using quillaja saponin as an emulsifier. After two-weeks storage at $50^{\circ} \mathrm{C}$, the retentions of EPA and $\mathrm{DHA}$ were about 0.8 in encapsulated

\section{Acknowledgement}

This research was supported by grants from the Project of the NARO Bio-oriented Technology Research Advancement Institution (the special scheme project on vitalizing management entities of agriculture, forestry and fisheries).

\section{References}

[1] Grandois, JL.; Marchioni, E.; Zhao, M.; Giuffrida, F.; Ennahar, S.; Bindler, F. Investigation of natural phosphatidylcholine sources: separation and identification by liquid chromatography-electrospray ionization-tandem mass spectrometry (LC-ESI-MS2) of Molecular Species. Journal of Agricaltural Food and Chemistry, 2009, 57 (14), 6014-6020.

[2] Gomez-Estaca, J.; Comunian、T.A.;.Montero, P.; Ferro-Furtado, R.; Favaro-Tirindade, C.S. Encapsulation of an astaxanthin-containing lipid extract from shrimp waste by complex coacervation using a novel gelatin-cashew gum complex. Food Hydrocolloids, 2016, 61, 155-162.

[3] Haider, J.; Majeed, H.; Williams, P.A.; Safdar, W.; Zhong, F. Formation of chitosan nanoparticles to encapsulate krill oil (Euphausia superba) for application as a dietary supplement. Food Hydrocolloids, 2017, 63, 27-34.

[4] Sanguansri,L.; Shen, Z.; Bhail, S.; Cheng, LJ.; Ying, DY.; Augustin, MA. Novel formulations and process for development of microencapsulated krill oil. http://aocs.files.cms-plus.com/Meetings/Affliated/LSanguansri_Novelformulations.pdf

[5] Yamada, H.; Kikuchi, S.; Hakozaki, M.; Motodate, K.;Nagahora, N.; Hirose, M. 8hydroxyeicosapentaenoic acid decreases plasma and hepatic triglycerides via activation of peroxisome proliferator-activated receptor alpha in high-fat diet-induced obese mice. Journal of Lipids, 2016, Article ID 7498508, 9 pages.

[7] Ghani, AA.; Adachi, S.; Sato, K.; Shiga, H.; Iwamoto, S.; Neoh, TL.; Adachi, S.; Yoshii, $\mathrm{H}$. Effects of oil-droplet diameter and dextrose equivalent of maltodextrin on the surface-oil ratio of microencapsulated fish oil. Journal of Chemical Engineering of Japan. 2017, 50, 799-806,

[8] Ghani, AA.; Adachi, S.; Shiga, H.: Neoh TL.; Adachi, S.; Yoshii, H. Effect of different dextrose equivalents of maltodextrin on oxidation stability in encapsulated fish oil by spray drying. Bioscience, Biotechnology, and Biochemistry, 2017, 81, 705-711.

[9] Soottitantawat, A.; Yoshii, H.; Furuta, T.; Ohgawara, M.; Linko,P. Microencapsulation by spray drying: Influence of emulsion size on the retention of volatile compounds. Journal of Food Science, 2003, 68, 2256-2262. 